\title{
A LAGRANGIAN PARTICLE MODEL WITH CHEMICAL REACTIONS: APPLICATION IN REAL ATMOSPHERE
}

\author{
Stefano Alessandrini ${ }^{1}$ and Enrico Ferrero ${ }^{2}$ \\ ${ }^{1}$ CESI RICERCA, Milano, Italy \\ ${ }^{2}$ Università del Piemonte Orientale, Alessandria, Italy
}

\begin{abstract}
In this work a lagrangian particle model able to account for simple chemical reactions between $\mathrm{NO}$ and $\mathrm{O}_{3}$ (Alessandrini et al., 2007) has been improved in order to consider the photolysis of $\mathrm{NO}_{2}$. A system of chemical equations is numerically solved on an eulerian grid, while the particles trajectories are moved in a lagrangian frame. The NOx emissions of a power plant in real atmosphere, situated in a complex topography environment, have been considered as a test case. The meteorological model RAMS has been applied to build the wind field together with the interface code MIRS to compute turbulence parameters, requested for the dispersion simulations. The plume transitions over an air quality station, allowing for a comparison between the measured and computed concentrations of all the reaction's compounds $\left(\mathrm{NO}, \mathrm{NO}_{2}\right.$ and $\mathrm{O}_{3}$ ), have been simulated by the lagrangian particle model. The simulated episodes refer to the diurnal time, when the ultraviolet radiation activates the $\mathrm{NO}_{2}$ photolysis making necessary the model complete set of chemical equations. In order to reduce computational cost and improve the accuracy of the background $\mathrm{O}_{3}$ concentration representation, the concept of concentration deficit carried by the particles is proposed and tested. This new method does not need to release a big amount of particles filling the whole domain, but only the inside plume particles should be accounted for. Comparisons between $\mathrm{NO} / \mathrm{NO}_{2}$ 's concentrations ratio are presented in term of scatter plots and statistical indexes analysis. The satisfactory results suggest that the model can be used in practical applications in real atmosphere also for regulatory purposes when the $\mathrm{NO}_{2}$ concentration limits are imposed by the legislation.
\end{abstract}

Key words: Atmospheric dispersion, NO, chemistry model, Lagrangian Particle Model, photo-stationary equilibrium.

\section{INTRODUCTION}

The chemical reactions of the pollutants released by a source with the background ambient chemical compounds are a very important task for the air quality and regulatory models; for example when dealing with $\mathrm{NO}_{\mathrm{x}}$ source and the related photochemical pollution. This aim is generally achieved in the frame of the Eulerian models by considering very complicated chemical schemes, including a large set of reactions and assuming the times scale for turbulence and chemistry such that to allow equilibrium hypothesis (Jacobson, 2001, Griffin et al., 2002, Sokhi et al., 2006, Sokhi et al., 2007). In this way the segregation due to the correlation between the concentration of the chemical compounds is neglected and it is not needed a turbulent model providing these terms. However, in many pollution phenomena, when the time and spatial scales are small, as for example close to the source or in urban environment, this assumption cannot be made and non equilibrium must be considered in order to avoid a too fast reaction rate. The covariance of the concentration should also be known if one had to simulate chemical reactions at small temporal and spatial scales, where the chemical equilibrium is not yet attained. Thus new model should be developed. To this aim, the Lagrangian stochastic models (see for instance van Dop et al., 1985; Luhar and Britter, 1989; Hurley and Physick, 1991; Tinarelli et al., 1994; Du et al., 1994) seem to be promising even if, up to now, they have been developed only for simplified conditions, as homogeneous and isotropic turbulence (Crone et al., 1999, van Dop et al., 2001). Actually, these models allow considering small-scale dispersion and calculating the cross correlation terms (Thomson, 1990; Borgas and Sawford, 1994). Nevertheless, Lagrangian models accounting only for simple chemical processes remain pioneer works that cannot deal at all with real cases. Eulerian models are usually applied over regional or synoptic scale domains in order to assess the air quality due to environmental pollution generated by sparse emissions both from industrial activities and, in general, from any human activities. In previous works (Alessandrini et al., 2007, Alessandrini, 2006), we presented a modified Lagrangian stochastic model for reactive pollutants. Although this model is a one-particle model, and hence is not able to predict concentrations fluctuations, a good agreement with laboratory experiments was found. Further, a method to avoid the use of great amount of particles was proposed. These results allow applying our model to real cases, where the domain is large and hence the simulation of the ozone background concentration would be very difficult with a standard particle model. While in our previous work (Alessandrini et al., 2007) we applied our model to a wind tunnel experiment realized in neutral conditions, here we test the models against real data. Further, the chemical scheme is improved in order to include $\mathrm{NO}_{2}$ photolysis. The results of the simulation are compared with the measured data at a station.

\section{DISPERSION MODEL}

SPRAY (Alessandrini et al., 2005a) is a Lagrangian stochastic particle model designed to study the pollutants dispersion in complex terrain. It is based on the Langevin equation for the turbulent velocities (Thomson, 1987), whose coefficients depend on a solution of the Fokker-Planck equation for a given Eulerian probability density function (PDF) of the turbulent velocity and on the inertial range turbulence theory respectively. In the two horizontal directions the PDF is assumed to be Gaussian. In the vertical direction the PDF is assumed to be non-Gaussian, so to deal with convective conditions. The equations prescribing the evolution of the vertical velocity fluctuation $w$ and the displacement $z$ are the following:

$$
\begin{gathered}
d w=a(z, w) d t+\sqrt{C_{0} \varepsilon d t} d \mu \\
d z=w d t
\end{gathered}
$$


where $d \mu$ is a Wiener process with zero mean and unit variance, $C_{0}$ is a constant and $\varepsilon$ is the dissipation rate of turbulent kinetic energy. $a(Z, W)$ must be determined by solving the Fokker-Planck equation, obtaining:

$$
a(z, w)=\frac{1}{P}\left(B_{0} \frac{\partial P}{\partial w}+\Phi\right)
$$

with $B_{0}=\frac{1}{2} C_{0} \varepsilon$ and, as suggested by Thomson, (1987),

$$
\Phi=-\frac{\partial}{\partial z} \int_{-\infty}^{w} w P(z, w) d w
$$

where $P(z, w)$ is the PDF that must be prescribed from the available measurements or parameterizations. In the present work, we used the Gram-Charlier PDF .

The dispersion model is coupled to the circulation model RAMS, which provides the mean flow.

\section{CHEMICAL SCHEME}

Formation of $\mathrm{NO}_{2}$ occurs when $\mathrm{NO}$ is emitted in an atmosphere containing $\mathrm{O}_{3}$. During the daytime, photodissociation of $\mathrm{NO}_{2}$ by absorption of ultra-violet radiation leads to the production of $\mathrm{NO}$ and $\mathrm{O}_{3}$. So the chemical reactions considered by our model are:

$$
\begin{aligned}
& \mathrm{NO}+\mathrm{O}_{3} \stackrel{k}{\rightarrow} \mathrm{NO}_{2}+\mathrm{O}_{2} \\
& \mathrm{NO}_{2}+\mathrm{O}_{2}+h v \stackrel{J}{\rightarrow} \mathrm{NO}+\mathrm{O}_{3}
\end{aligned}
$$

where $k$ depends on temperature and is around $0.4 \mathrm{ppm}^{-1} \mathrm{sec}^{-1}$ while $J$ depends on solar radiation and ranges between 0 during the night and $0.4 \mathrm{~min}^{-1}$ in the full sunlight. The discretized form adopted for the set of chemical equations is:

$$
\begin{aligned}
& \left\langle c_{N O}\left(\mathbf{x}_{j}, t_{1}\right)\right\rangle=\left\langle c_{N O}^{*}\left(\mathbf{x}_{j}, t_{1}\right)\right\rangle-k \Delta t\left\langle c_{N O}^{*}\left(\mathbf{x}_{j}, t_{1}\right)\right\rangle\left\langle c_{O_{3}}^{*}\left(\mathbf{x}_{j}, t_{1}\right)\right\rangle+j \Delta t\left\langle c_{N O_{2}}^{*}\left(x_{j}, t_{1}\right)\right\rangle \\
& \left\langle c_{N O_{2}}\left(\mathbf{x}_{j}, t_{1}\right)\right\rangle=\left\langle c_{N O_{2}}^{*}\left(\mathbf{x}_{j}, t_{1}\right)\right\rangle+k \Delta t\left\langle c_{N O}^{*}\left(\mathbf{x}_{j}, t_{1}\right)\right\rangle\left\langle c_{O_{3}}^{*}\left(\mathbf{x}_{j}, t_{1}\right)\right\rangle-j \Delta t\left\langle c_{N O_{2}}^{*}\left(x_{j}, t_{1}\right)\right\rangle \\
& \left\langle c_{O_{3}}\left(\mathbf{x}_{j}, t_{1}\right)\right\rangle=\left\langle c_{O_{3}}^{*}\left(\mathbf{x}_{j}, t_{1}\right)\right\rangle-k \Delta t\left\langle c_{N O}^{*}\left(\mathbf{x}_{j}, t_{1}\right)\right\rangle\left\langle c_{O_{3}}^{*}\left(\mathbf{x}_{j}, t_{1}\right)\right\rangle+j \Delta t\left\langle c_{N O_{2}}^{*}\left(x_{j}, t_{1}\right)\right\rangle
\end{aligned}
$$

where the subscript $j$ stands for the cell number, the asterisk indicates the old concentration in the cell obtained after the Lagrangian particles displacements but before the chemical reaction. In the previous system the $\mathrm{O}_{2}$ concentrations are neglected because this substance is always present in excess and his variation in time and space does not influence the kinetic $J$ of the reaction.

Following Chock and Winkler (1994 a and b), chemistry and dispersion are treated separately and sequentially, each particle $(n)$ released by the source may bring mass of different substances. At each time step, the particle position $X^{(n)}(t)$ is updated using the stochastic model equation, then the concentrations of each substance are calculated in a fixed Eulerian grid and the chemistry is computed.

Then the mass $(M)$ of the different substances $(\alpha)$ are redistributed to each particle $(n)$ in the cell $(j)$ through the following scheme:

$$
\begin{aligned}
& M_{\alpha}^{(n)}\left(t_{1}\right)=\left\langle c_{\alpha}\left(\mathbf{x}_{j}, t_{1}\right)\right\rangle \frac{V_{j}}{N_{j}} \quad \text { if } \quad\left\langle c_{\alpha}^{*}\left(\mathbf{x}_{j}, t_{1}\right)\right\rangle=0 \\
& M_{\alpha}^{(n)}\left(t_{1}\right)=M_{\alpha}^{(n)}\left(t_{0}\right) \frac{\left\langle c_{\alpha}\left(\mathbf{x}_{j}, t_{1}\right)\right\rangle}{\left\langle c_{\alpha}^{*}\left(\mathbf{x}_{j}, t_{1}\right)\right\rangle} \text { otherwise; }
\end{aligned}
$$

where $t_{0}$ and $t_{1}$ indicates the time before and after the reaction, $V_{j}$ and $N_{j}$ are the volume and the number of particles inside the cell.

Treating background species as static fields is not a reasonable approximation in the case of $\mathrm{O}_{3}$. In fact, this method is clearly inadequate inside the plume where the average concentration is usually lower than the background value and changes along and across the wind direction (Hegg et al., 1977). Ideally, species such as ozone would be represented by releasing extra particles throughout the three-dimensional model domain. The number of particles required to adequately represent ozone throughout the atmosphere becomes computationally prohibitive (Middleton et al., 2007) as the domain dimension is greater than $1 \times 1 \mathrm{~km}^{2}$.

In order to overcome the limits of this method, we allow the plume particles to carry, together with $\mathrm{NO}$ and $\mathrm{NO}_{2}$ concentrations, also the "deficit" of the $\mathrm{O}_{3}$ concentration respect to the background. In other words, we describe the

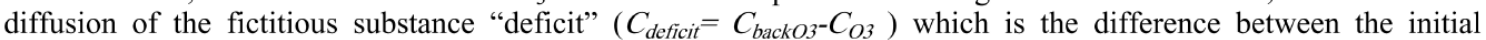
background concentration field $C_{\text {backO3 }}$ (supposed to be constant) and the real $\mathrm{O}_{3}$ concentration field $\left(C_{O 3}\right)$. $C_{\text {deficit }}$ is different from zero only where chemical reactions, which modify the initial background concentration, occur. The chemical scheme does not change because the real $\mathrm{O}_{3}$ concentration field $\left(C_{O 3}\right)$ is easily computed as the difference between the constant background and the deficit concentration at each time step including a chemical reaction. Then, 
the chemical scheme is applied and the new ozone concentration is obtained, so the deficit concentration $\left(\mathrm{C}_{\text {deficit }}\right)$ is computed again and the particles are dispersed by the turbulent flow.

\section{RESULTS AND DISCUSSION}

The case considered for the evaluation refers to a gas-power plant located in the north of Italy. The substances released by three stacks are for the $95 \%$ constituted by $\mathrm{NO}$ and the $5 \%$ by $\mathrm{NO}_{2}$. At approximately $4 \mathrm{~km}$ south of the power plant, $\mathrm{NO}, \mathrm{NO}_{2}$ and $\mathrm{O}_{3}$ hourly average concentrations are measured continuously by an air quality station, located on a hill $300 \mathrm{~m}$ higher than the power plant (Figure 1).

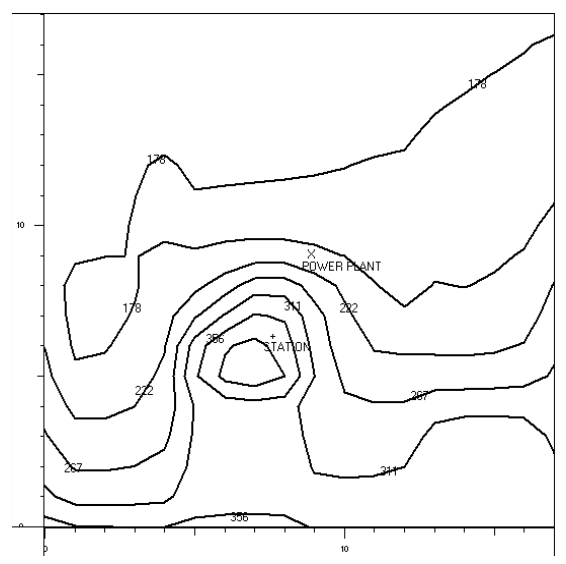

Figure 1. Area covered by the domain of the dispersion simulations: Power plant and air quality station locations are shown

Considering that the station is located in a rural area surrounded by only a small village in the south, it is possible to isolate the power plant $\mathrm{NO}_{\mathrm{x}}$ contribution from the other sources, in north, north-east wind conditions. Hence, in these situations, the $\mathrm{NO}_{\mathrm{x}}$ plume transition over the station can be clearly detected. A period lasting 10 days, from the $12^{\text {th }}$ to $22^{\text {th }}$ of March 2007, has been chosen because several plume transitions over the station, usually between 6 and 11 LST, were observed and, in general, clear sky and high-pressure conditions occur. The wind and turbulence fields have been built by the model system RAMS 6.0-MIRS (Alessandrini et al. 2005b), using the ECMWF analysis fields as boundary conditions, and performing a 4-d var data assimilation with the meteorological measurements of two ground stations located close to the power plant and the air quality gauges. Three nested grids have been used with a grid spacing of 12, 4 and $1 \mathrm{~km}$ respectively. The smallest grid is $17 \times 17 \mathrm{~km}^{2}$ large and represents the dispersion simulations domain. A variable time step scheme has been used for the lagrangian particles displacement while the chemical reactions time step was set equal to $20 \mathrm{~s}$. The cells for the concentrations computation have been set equal to $100 \times 100 \times 50 \mathrm{~m}^{3}$ and constant all over the domain. The amount of particles released every $5 \mathrm{~s}$ changes during the simulation, depending on the emission ratio, in order to maintain constant and equal to $0.8 \mu \mathrm{g}$ the NO mass assigned to each particle. The reaction rates $k$ and $J$ are computed every hour using the following equations (IUPAC 2005 and Parrish et al. 1983):

$$
\begin{aligned}
& k=3.1 \cdot 10^{3} \cdot \exp (-1450 / T) \\
& J=0.01305 \cdot \exp (-0.36 / \cos (\alpha))
\end{aligned}
$$

where $T$ is the air temperature, computed by RAMS, and $\alpha$ is the complementary of the solar elevation angle. In the case of $j$, the equation refers to clear sky conditions and hence, accounting for cloud cover, more realistic values should be lower. The ozone background concentration $\left(C_{\text {backO3 }}\right)$ have been set constant during each day and equal to the measured values during the last hours before the plume transition over the air quality station. During the

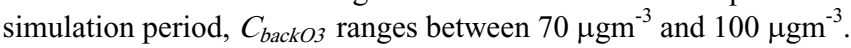

In the dispersion diagram on the left of Figure $2, \mathrm{NO}_{2} / \mathrm{NO}_{\mathrm{x}}$ computed ratios are compared with the measurements. In order to consider significant situations with plume transitions, we have considered only the diurnal cases with northerly winds and when both the models and the measurements of $\mathrm{NO}_{2}$ were greater than $5 \mu \mathrm{gm}^{-3}$. In Figure 2 model results are also compared with the $\mathrm{NO}_{2} / \mathrm{NO}_{\mathrm{x}}$ values that would occur in photo-stationary equilibrium situations. These values have been obtained by the equation suggested by Seinfeld (1986), introducing the $\mathrm{NO}_{\mathrm{x}}$ concentrations computed by Spray and the background value as the initial ozone concentration. In these cases, the photo-stationary ratio $\psi=\frac{k\left[! O \mathrm{O} \mathrm{O}_{3}\right]}{J\left[\mathrm{IO}_{2}\right]}$ should be equal to 1 (Hegg et al., 1977). In general inside a plume $\psi$ is greater

than 1 at short distances from the source when the time scales of turbulence over the spatial scale of the plume are smaller than the time scales of chemical reactions. In general, the $\mathrm{NO}_{2} / \mathrm{NO}_{\mathrm{x}}$ computed values show a good agreement with a little underestimation of the measurements. This could be caused by an overestimation of the computed photodissociation rate $J$ which forces the model towards lower $\mathrm{NO}_{2}$ concentrations. It is important to stress that, even if the 
measured values of global radiation indicate, in general, clear sky conditions, we cannot exclude the presence of a light fog especially during the first hours after the sun rise (when most of the shown values are computed). On the other hand, the model shows to be able to reproduce photo-stationary equilibrium at the station location that should be valid in this case. In fact, the ground level concentrations measurements are taken $4 \mathrm{~km}$ far from the stack where a lot of ambient air has entered and has been well mixed inside the plume (Janssen, 1986).
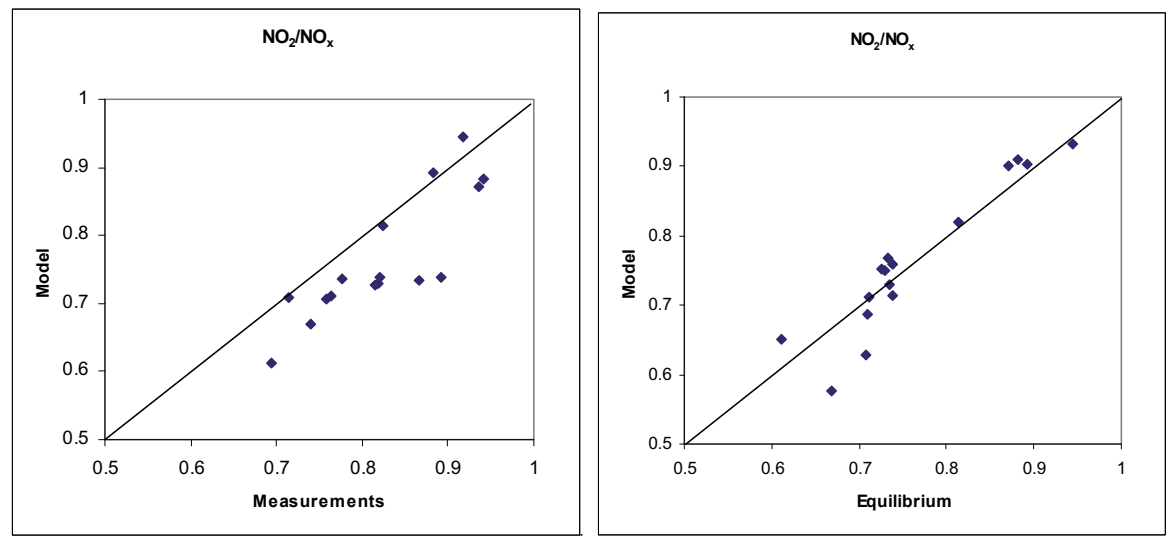

Figure 2. $\mathrm{NO}_{2} / \mathrm{NO}_{\mathrm{x}}$ computed values vs measurements (left) and photo-stationary equilibrium values (right)

The results are confirmed by the model evaluation performed by calculating statistical indexes that are shown in Table 1 and Table 2. The performance of the model, compared with measurements, is satisfactory except for the underestimation indicated by the value of fraction bias (FB). This underestimation becomes a very small overestimation when comparing model results and equilibrium values.

In Figure 3, $\mathrm{NO}, \mathrm{NO}_{2}$ and $\mathrm{NO}_{\mathrm{x}}$ concentration fields, computed by Spray at ground level in a diurnal situation, are shown as an example. The location of the maximum level concentration is substantially the same for the three substances, confirming what also found by other authors (Middleton et al. 2007, Janssen 1987).

Table 1. Statistical comparison between $\mathrm{NO}_{2} / \mathrm{NO}_{\mathrm{x}}$ computed values and the measurements.

\begin{tabular}{|l|c|c|c|c|c|c|c|c|}
\hline & Mean & Sigma & Bias & Nmse & Cor & Fa2 & FB & fas \\
\hline Measurements & 0.82 & 0.076 & 0 & 0 & 1 & 1 & 0 & 0 \\
\hline Spray & 0.76 & 0.088 & -0.059 & 0.0091 & 0.85 & 1.0 & -0.075 & -0.15 \\
\hline
\end{tabular}

Table 2. Statistical comparison between $\mathrm{NO}_{2} / \mathrm{NO}_{\mathrm{x}}$ computed and photo-stationary equilibrium values.

\begin{tabular}{|l|c|c|c|c|c|c|c|c|}
\hline & Mean & Sigma & Bias & Nmse & Cor & Fa2 & FB & fas \\
\hline Equilibrium & 0.76 & 0.10 & 0 & 0 & 1 & 1 & 0 & 0 \\
\hline Spray & 0.76 & 0.088 & 0.0011 & 0.0024 & 0.94 & 1.0 & 0.0014 & 0.16 \\
\hline
\end{tabular}

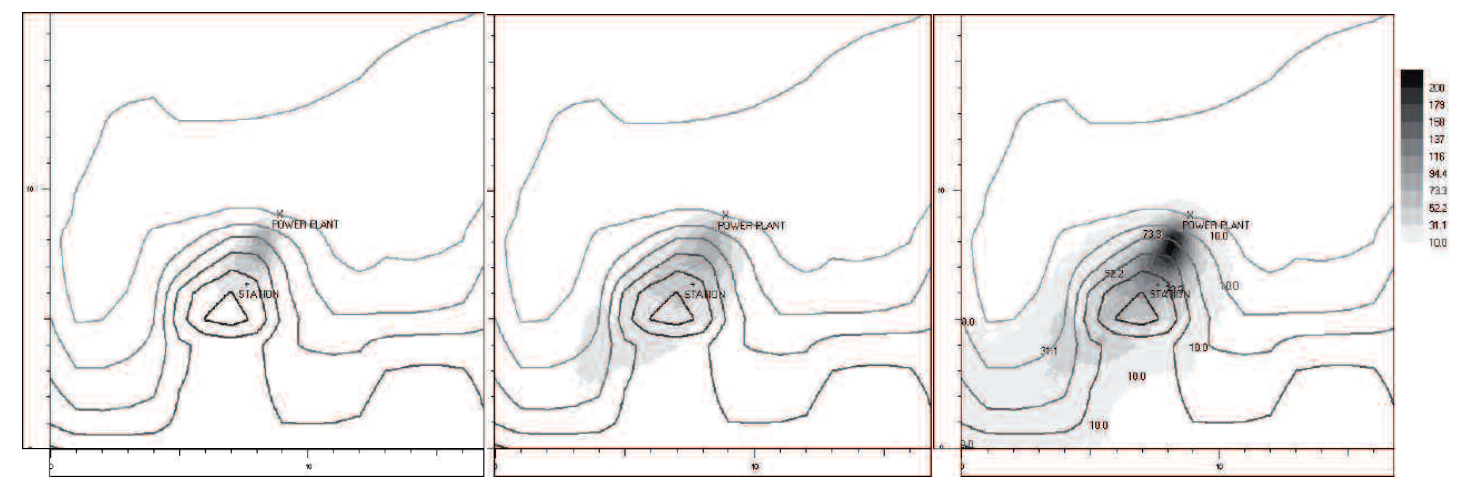

Figure 3. Ground level concentration fields $\left(\mu \mathrm{gm}^{-3}\right)$ of (from left to right) $\mathrm{NO}, \mathrm{NO}_{2}$ and $\mathrm{NO}_{\mathrm{x}}$ computed by Spray at 10 LST of $12-$ 03-2007. Power plant and air quality station locations are also shown

Acknowledgements: This work has been financed by the Research Fund for the Italian Electrical System under the Contract Agreement between CESI RICERCA and the Ministry of Economic Development - General Directorate for Energy and Mining Resourcesstipulated on June 21, 2007 in compliance with the Decree n. 73 of June 18, 2007. 


\section{REFERENCES}

Alessandrini S., M. Costa, Anfossi D., Evangelisti M., 2005 a: Improvement of the SPRAY code performance in the comparison with law limits. Internal Report CESI, n A5/053304.

http://www.ricercadisistema.it/Documenti/SintesiDoc.aspx?idN=1248\&idD=312729

Alessandrini, S., Trini Castelli S., Ferrero E., Anfossi D. 2005 b: Influence of turbulence closure in the simulation of flow and dispersion on complex terrain. Int. J. Environment and Pollution, 24, 154-170.

Alessandrini, S. 2006: Development of the evaluation instruments for the environment aspects important for the planning of the electrical power distribution network. Internal report CESI RICERCA $\mathrm{n}$ 06007724, http://www.cesiricerca.it/Documenti/SintesiDoc.aspx?idN=1047\&idD=246

Alessandrini, S., Ferrero E., Belfiore G., 2007: A Lagrangian particle model with chemical reactions. J. Env. Pollut., (submitted).

Borgas, M.S. and B.L.Sawford, 1994: A Family of Stochastic Models For Particle Dispersion in Isotropic Homogeneous Stationary Turbulence. J. Fluid Mech., 279, 69-99.

Crone, G.C., Dinar N., van Dop H., Verver G.H.L., 1999: A Lagrangian approach for modelling turbulent transport and chemistry. Atm. Env., 33, 4919-4934.

Chock, D.P., Winkler S.L., 1994: A particle grid air quality modeling approach, 1. Dispersion aspect, J. of Geoph. Res., 99 D1, 1019-1031.

Chock, D.P., Winkler S. L., 1994: A particle grid air quality modeling approach, 2. Coupling with Chemistry. J. of Geoph. Res., 99 D1, 1033-1041.

Du, S., Wilson J.D. and Yee E., 1994: Probability density functions for velocity in the convective boundary layer and implied trajectory models. Atmos. Environ., 28, 1211-1217.

Ferrero, E. and D. Anfossi, 1998: Comparison of PDFs closure schemes and turbulence parameterizations in Lagrangian stochastic models, Int. Jour. of Environ. and Poll., 9, No. 4 , 384-410.

Griffin, R.J., Dabdub D., Kleeman M.J., Fraser M.P., Cass G.R. and Seinfeld J.H., 2002: Secondary organic aerosol: III. Urban/regional scale model of size- and composition-resolved aerosol. J. Geophys. Res., (107), 101029/2001JD000544.

Hegg, D., Hobbs P. V., Radke L. F. and Harrison H., 1977: Reactions of ozone and nitrogen oxides in power plant plumes. Atmos. Env., 11, 521-526.

Hurley, P.J. and W. Physick, 1991: A skewed homogeneous Lagrangian particle model for convective conditions. Atmos. Environ., 25A, 1313-1325.

IUPAC, 2005: Evaluated kinetic and photochemical data for atmospheric chemistry- IUPAC subcommittee on gas kinetic data evaluation for atmospheric chemistry. http://www.iupac-kinetic.ch.cam.ac.uk/index.html.

Jacobson, M.Z., 2001: GATOR-GCMM: A global- through urban-scale air pollution and weather forecast model. 1. Model design and treatment of subgrid soil, vegetation, roads, rooftops, water, sea ice, and snow. J. Geophys. Res., 106, 5385-5401.

Janssen, L.H.J.M., 1986: Mixing of ambient air in a plume and its effects on the oxidation of NO. Atm. Env. ,19, 587-595.

Janssen, L.H.J.M., 1987: A classification of NO oxidation rates in power plants plumes based on atmospheric conditions. Atm. Env., 22, 43-53.

Luhar, A.K. and R.E. Britter, 1989: A random walk model for dispersion in inhomogeneous turbulence in convective boundary layer. Atmos. Environ., 23, 1911-1924.

Middleton, D.R., Jones A.R., Redington A.L., Thomson D.J., Sokhi R.S, Luhana L., Fisher B.E.A., 2007: Lagrangian modelling of plume and chemistry for secondary pollutants in large industrial plume, Atm. Env., 42, 415-427.

Parrish, D.D., Murphy P.C., Albritton D.L., Fehsenfeld F.C., 1983: The measurements of the photodissociation rate of NO2 in the atmosphere. Atmospheric Environment, 17, n 7, 1365-1379.

Seinfeld, J.H., 1986: Air polluton, Atmospheric Chemistry and Physics of air pollution, 118-121.

Sokhi, R.S., San José R., Kitwiroon N., Fragkou E., Pérez J.L. and Middleton D R., 2006: Prediction of ozone levels in London using the MM5-CMAQ modelling system. Env. Model. and Software J., 21(4), 566-576.

Sokhi, R. S., H. Mao, S.T.G. Srimath, S. Fan, N. Kitwiroon, L. Luhana, J. Kukkonen, M. Haakana, A. Karppinen, K. D. van den Hout, P. Boulter, I.S. McCrae, S. Larssen, K.I. Gjerstad, R. San José, J.G. Bartzis, P. Neofytou, P. van den Breemer, S. Neville, A. Kousa, 2007: An integrated multi-model approach for air quality assessment: development and evaluation of the OSCAR Air Quality Assessment System. Environ. Model. Softw., 23, 268-281.

Thomson, D.J., 1987: Criteria for the selection of stochastic models of particle trajectories in turbulent flows. J. of Fluid Mech., 180, 529-556.

Thomson. D.J., 1990: A stochastic model for the motion of particle pairs in isotropic high-Reynolds-number turbulence, and its application to the problem of concentration variance. J. of Fluid Mech., 210, 113-153.

Tinarelli, G., D. Anfossi, G. Brusasca, E. Ferrero, U. Giostra, M.G. Morselli, J. Moussafir, F. Tampieri, F. Trombetti, 1994: Lagrangian particle simulation of tracer dispersion in the lee of a schematic two-dimensional hill. J. of App. Met., 33, No. 6, 744-756.

Trini Castelli, S., 2000: MIRS: a turbulence parametrisation model interfacing RAMS and SPRAY in a transport and diffusion modelling system. Rap. Int. ICGF/CNR No 412/ 2000, Torino, Italy.

van Dop, H., Nieuwstadt F.T.M. and. Hunt J.C.R., 1985: Random walk models for particle displacements in inhomogeneous unsteady flow. Phys. Fluids, 28, 1639-1653.

van Dop, H., 2001: The evaluation of a Lagrangian model for turbulent transport and chemistry. Phys. of Fluids, 43, 13311342. 